\title{
Appeals, Sexual Images, Visual Metaphors and Themes: Differences in Condom Print
}

Ads across Four Continents

Jo-Yun Li, University of South Carolina, USA

Lulu Rodriguez, University of Illinois at Urbana-Champaign, USA

\begin{abstract}
This study examined condom print advertisements published in four continents (Europe, Asia, North America and South America) to determine differences in emotional appeals used, the presence of sexually-charged images, the visual metaphors applied, and the themes stressed. The results obtained from a content analysis show the dominance of humor appeal and the downplaying of nakedness and sexual scenes to promote condom use. The European advertisements made greater use of sexual images. Only a few ads, mostly from Asia, used metaphors. In Europe, Asia, and North America, the enhancement of sexual pleasure was the dominant frame. In South America, the major theme focused on preventing pregnancy.
\end{abstract}

Keywords: condom print ads; cultural differences in print advertising; sexual images in condom ads; visual metaphors in condom ads; condom ad themes 


\section{Introduction and Statement of the Problem}

Some think that because of advances in communication technology, the world has practically become a global village. Advertisers and marketers take this to mean that with the increasing homogeneity of audiences, promotion strategies can be standardized across countries, enhancing the ads' ability to persuade consumers regardless of time and place. Among the benefits of employing such a uniform approach, two of the most frequently mentioned are savings in costs and the facility to create a unified image for a brand (Tansey, Hyman and Zinkhan, 1990). Keegan (1989) disagrees, stating that understanding cultural differences is a prerequisite for successful international advertising. He stresses that there are still formidable cultural barriers that often render standardized advertising impractical. Understanding cultural differences is important to take on the creative challenge of communicating to people of diverse cultural backgrounds. To make a dent, advertising and marketing strategies, therefore, should resonate with the local cultures and respond to local needs.

Consequently, analyzing cross-cultural differences in advertising expression has become a growing area of research. Over the past three decades, a number of studies (e.g., Mueller 1991; Tansey, Hyman, and Zinkhan, 1990) have made valuable contributions to the understanding of the differences among cultures in terms of informational and emotional content in advertisements as well as the use of humor, comparative cues, and sex role portrayal.

Cultural practices and cultural sensitivities are important considerations, especially among those charged with the task of communicating controversial and even taboo topics. Among these topics are sex, sexual orientations, and sexual practices. While some societies are relatively more tolerant to a robust and open discourse about such topics, others remain 
decidedly uneasy with these subject matters, a challenge to which those who market condoms and promote condom use are well aware. Open discussions of these topics are discouraged by the cultural norms of some nations while in some places, the terms of discourse are written into law. Some cultures refrain from putting a spotlight on these topics that others see as harmless.

Several factors appear to be behind the increasing willingness of media outlets around the globe to feature condom commercials: the devastation wrought by HIV/AIDS, the increasingly sexual nature of many TV shows, the willingness of several local media outlets to test the waters by publishing or airing condom ads, and the loosening restrictions on prescription drug advertising (Wilke, 2001). These ads have trumpeted the use of condoms to prevent pregnancy, to curb the spread of sexually transmitted diseases, and to heighten the sexual experience.

How much freedom in sexual expression is evident in ads that extol the benefits and advantages of condom use? Finding the answer to this question will give advertising strategists ammunition they can use to deftly handle this communication challenge. This study aims to investigate the dominant frames used in condom print ads disseminated in four continents (Asia, Europe, North America and South America), how these ads made use of naked bodies and/or sexual scenes in their visual presentations, the emotional appeals they employed, and the visual metaphors highlighted to drive home the message. The findings are expected to assist business people navigate the potential obstacles that come with working in different cultural milieus. The results of such investigations are especially valuable in light of increased international trade and the subsequent need to communicate effectively to people of various cultures. The more advertisers are able to understand the nature of these differences, 
the better able they are to design advertisements that are effective on an international level.

\section{Literature Review and Theoretical Framework}

\section{Emotional Appeals in Advertising}

According to Ambekar (2009), "advertising appeals are designed so as to create a positive image of the individuals who use certain products" (para. 2) and thus influence consumers' purchasing decisions. Products and services are packaged in ways that explain to consumers why they should purchase what is being marketed (Kotler, 1991). Berkman and Gilson (1987) define advertising appeal as a creative attempt to inspire consumers' purchasing motives and influence their attitude toward a specific product or service. Advertising appeals are applied to attract attention, change consumers' conception of the product, and to affect them emotionally (Belch and Belch, 1998; Schiffman and Kanuk, 2007).

Of these appeals, the most commonly used are the rational and emotional appeals (Chu, 1996). Emotional appeals include the use of humor, fear and sadness in ad presentations. Ambekar (2009) explains that an emotional appeal caters to "an individual's psychological and social needs for purchasing certain products and services" (para. 3). Because emotions can be understood by people around the world, one can say that emotions are a universal language. Thus, when used as communication devices, emotional appeals can transcend cultural, linguistic, demographic, and social boundaries (Parkinson, 1995). Gordon (2005) views emotions as one of the most significant factors that influence people's decision-making process because emotions direct decisions and can be the catalyst that causes decisions to be made faster. Addressing the emotional side can assist significantly in gaining the acceptance of decisions made (Gordon, 2005). Wallbott and Scherer (1986), conducting research in 27 countries in five continents, found that the representation of emotion affects how audiences 
perceive a particular topic or issue.

Out of the range of possible human emotions, persuasive communication campaigns have often focused on fear. This is because for most people, fear has a significant effect on behavior (Tanner, Hunt, and Eppright, 1991), leading them to find ways of removing or coping with the perceived threat and therefore the danger (Sternthal and Craig, 1974). Communication practitioners have long taken advantage of this relationship by using the threat of danger to evoke fear and thus enhance behavioral change toward the recommended practice. Thus, to increase people's awareness of the advantages of condom use, ads frequently utilize threatening information (often embedded in fear appeals) to heighten people's concern and to act in accordance with the prescribed practices (Rogers, 1983).

Another emotional appeal involves the use of humor, which many consider as an excellent tool to catch attention and increase brand recognition, but does not necessarily improve product recall, message credibility, or buying intentions (Alden, et al., 1993). In other words, humor in ads familiarizes consumers with the product, helps develop positive feelings toward it, but may not have an impact on purchasing decisions. Many of the most memorable ad campaigns tend to be funny. Advertisers use this strategy knowing that audiences like to be entertained, but not "pitched." People generally tend to pay more attention to a humorous commercial than a factual or serious one, opening themselves up to be influenced. Levit (2005) argues that the best products to sell using humor are those that consumers have to think the least about. Products that are relatively inexpensive, and often consumable, such as condoms, can be represented without providing a lot of facts, which offers room for humor.

Sadness, another emotional appeal, has proven its worth in changing people's attitudes (e.g., 
Ambekar, 2009). Sad appeals are classified as negative because they provide a sympathetic sense of loss or insecurity (Mitchell et al., 2001). They have been shown to result in attitude change when they provide loss-related information, or information that emphasizes the disadvantages that may accrue to the individual and to society at large by not following a recommended behavior (Huang, 1997). Because sad appeals are easy to understand, they may play an important role in persuading people to use condoms.

According to Biswas, Olsen and Carlet (1992), "advertising appeals used in one country cannot simply be standardized or directly translated for use in another” (p. 80). For example, the key to funny advertising is assuring that the humor is appropriate to both product and customer. The balance between funny and obnoxious can often be delicate and culturally-dependent; a marketer must be certain that the positive effects outweigh the negative before an advertisement can be introduced. In other words, commercials that may leave some people gripping their sides from laughter may leave a bad taste in others' mouth.

Although countries may have socioeconomic similarities, differences in the ways ideas are expressed still can be found. Based on these, this study asks:

RQ1: What appeals (fear, humor, sadness) were used in the condom ads published in the four continents? Were the four places different in terms of the appeals used in the ads?

\section{Cultural differences in sexual depictions}

The use of explicit sexual imagery in consumer-oriented print advertising has become almost commonplace. These sexually charged images can be highly overt or extremely subtle. Sex appeal in advertising can be executed in a number of ways, including the use of double entendre, sexually attractive images, nudity, and suggestiveness (Bello, Pitts and Etzel, 1983; 
Rothschild, 1987). In this study, the use of sex in an advertisement was defined as the extent to which the advertisement employed nude, scantily dressed models of either gender, and any form of sexual suggestiveness, including the implicit or explicit benefit of gaining attractiveness in sexual or sensual ways through condom use. Post-advertising sales response studies have shown that sex can be very effective for attracting immediate interest, holding that interest, and in introducing a product that somehow correlates with that interest (Reichert, 2002).

Gallup \& Robinson (2011), an advertising and marketing research firm, reports that the use of the erotic is one of the more dangerous techniques for the advertiser. Weighted down with taboos and volatile attitudes, sex is a "code red" advertising technique that should be handled with care. This task becomes even more complex and controversial in multicultural environments where culturally-derived values and beliefs serve as norms that determine when certain images are appropriate and when they are not.

In short, whether consumers perceive condom ads as creative or obnoxious is highly influenced by their respective cultural backgrounds. Numerous scholars have observed that standardized advertising is not desirable because traditional perspectives, consumer tastes and government regulations vary considerably (Taylor and Raymond, 2000), especially for sex-related products.

Indeed sexual depictions are regarded differently in different parts of the world. For example, Fetto (2001) observes that some Americans do not like advertisements that feature too much sexuality, while some Europeans are highly accepting of nudity. Compared to the United States and countries in Europe, Asian and Middle Eastern nations tend to be more 
conservative about sex in ads (Frith \& Mueller, 2003). In some East Asian markets, religion and social values concerning modesty and the offensive nature of some products make it difficult to promote some socially sensitive products (Taylor and Raymond, 2000). Nelson and Peak (2005) also note that nudity in advertising vary cross-culturally, which means there is such thing as "localization in sexuality" (p. 347). Thus, this study asks:

RQ2: To what extent were naked bodies and sexual scenes present in the condom ads from the four continents? Were the four places different in terms of the presence of these visual elements in their ads?

\section{Visual Metaphors in Advertising}

Morris (2001) sees metaphors as devices that "enable the extension of ideas beyond experiences" (p. 944). Particularly persuasive, metaphors are ubiquitous in verbal and visual language. "It is through them that we are able to understand our world and express ourselves-from describing attitudes to defining objects" (p. 945). Metaphors have a fundamental role in thought processes as they provide a framework for organizing information about the world and for making sense of experiences (Kaplan, 1990). Peppers (1942) writes that root metaphors determine people's worldview by providing meaningful categories of perceptions and experiences. According to Lakoff and Johnson (1980), metaphors enable the understanding of one concept in terms of another.

Metaphors have been known to increase the persuasive power of speeches (Morris and Waldman, 2011) because they "appeal to the senses, enliven the discourse, and make it easier to attend to the arguments" (Bowers \& Osborn, 1966, p. 147). Applied to advertising, McQuarrie and Phillips (2004) found that compared to the impact of straightforward claims, consumers who saw ads with metaphors had more positive thoughts about the product being 
promoted.

Visual metaphors offer "a commentary on the details of life" (Zinkhan and Gelb, 1990). "The visual metaphor conveys the notion that the biggest (and most essential) part of the examined phenomenon remains unseen or under the surface. This dual function of visual metaphors- to organize information and to give it additional meaning — is not their only benefit" (Eppler, 2003, p. 82). Some studies indicate that visual metaphors facilitate recall (Kaplan 1992). "While verbal metaphors require receivers to create their own image (which may or may not be 'correct' or even make sense), a visual metaphor has done part of the 'work' of comprehending the comparison being generated" (Morgan and Reichert, 1999, p. 4). Based on the foregoing literature, this study asks:

RQ3: What visual metaphors were present in the condom ads? Were the four continents different in terms of the visual metaphors depicted in their ads?

\section{Visual Themes or Frames}

Framing theory posits that how an issue is characterized in mediated reports can have an influence on how the news is understood by audiences (Scheufele and Tewksbury, 2007). The frames employed by the mass media help develop interpretive schemas or "primary frameworks" among audience members so that they are able to classify information and interpret it meaningfully. As a macro-construct, "framing" refers to modes of presentation communicator's use to present information in a way that resonates with existing underlying schemas among audiences (Shoemaker \& Reese, 1996).

Visuals, like text, can operate as framing devices insofar as they make use of various rhetorical tools - metaphors, illustrations, symbols - that aim to capture the essence of an 
issue or event graphically. Through the application of these devices, a salient idea becomes easier to understand and easier to remember than other ideas (Entman, 1991). As Gamson and Stuart (1992) argue, visuals offer "a number of different condensing symbols that suggest the core frame" of the issue (p. 60). Visuals also help render a large amount of detail into practical frameworks that are relevant and appropriate to people's understanding of the everyday world. In this sense, visuals channel discursive possibilities for making sense of social phenomena; they legitimize (and thus facilitate) the grounds upon which some interpretations can be favored and others impeded. Based on this, it is pertinent to ask:

RQ4: What are the frames present in the condom ads? Were the four continents different in terms of frames used in the ads?

\section{Method}

To gather data for this study, a content analysis of condom print ads published in the continents of Asia, Europe, North America and South America was conducted. The objective was to examine the characteristics of messages embedded in these ads and the extent to which three emotional appeals were deployed, naked bodies and sexual images were shown, the visual metaphors that were used, and the themes emphasized.

To arrive at the sampling frame, a list of all condom manufacturers that market their products in each continent was constructed. The ads archived in each manufacturer's website were examined to compile the print ads distributed to these four markets over the past five years, 2007-2011. From each continent, 30 print ads were randomly selected from the sampling frame to produce a total sample size of 120 ads. The variables coded were 91) continent of publication, (2) advertising appeal used, (3) the presence of naked bodies and sexual scenes, (4) visual metaphors used, and (5) the dominant frame or message being communicated. 
The data were first analyzed to measure inter-rater reliability. Inter-rater agreement for the four categorical variables (emotional appeal used, metaphors used, presence or absence of naked bodies/ sexual images, and the themes emphasized) was assessed by calculating Scott's pi. Scott's pi represents the ratio of the actual difference between obtained and chance agreement to the maximum difference between obtained and chance agreement (Scott, 1955). The mean Scott's pi values for the four nominal variables were 1.0.

\section{Results and Discussion}

\section{Emotional Appeals}

The first research question asks for the emotional appeals (fear, humor, sadness) used in the condom ads and if there were differences among the four places in terms of the use of these appeals. Table 1 shows that of the 120 condom advertisements examined, $85 \%$ used humor to persuade customers, $13 \%$ used fear, and only $2 \%$ used the sadness appeal. Did the four continents differ in their use of emotional appeals? The results of a chi-square test suggest that the four locations did not differ significantly in terms of the use of these appeals $\left(x^{2}=10.17\right.$, $\mathrm{df}=6, \mathrm{p}=.118$ ). The dominance of humorous appeals can be seen across all four continents. Contrary to expectations, fear appeal was used far less frequently, suggesting advertisers' wariness with arousing dread among consumers. Across the board, sadness appeal was used the least (Table 1). Examples of ads that made use of these emotional appeals are shown in Figure 1.

The absence of significant differences across continents in terms of their use of emotional appeals runs counter to the propositions of Hall's (1981) theory of high- vs. low-context cultures. Hall predicts a difference between Asia and South America on the one hand and North America and much of Western Europe on the other in terms of "context." His typology 
suggests that the predominantly relational, collectivist, intuitive, and contemplative nature of Asians and South Americans means that they are more likely to deploy emotional appeals in ads, techniques that tend to enrich the communication context. On the other hand, the low-context cultures of North America and Europe are generally logical, linear, individualistic, and action-oriented, which make them value logic, facts, and directness. This implies the lesser probability of resorting to emotional appeals to strengthen arguments. Because communicators are expected to be straightforward, concise, and efficient in telling what action is expected in high-culture contexts, the presence of rational appeals were expected more in their ads.

Figure 1. Emotional appeals in condom ads

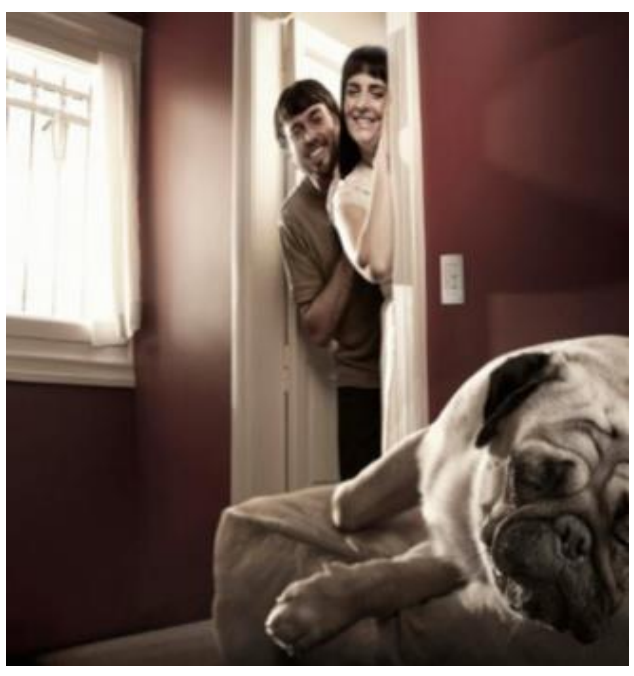

Appeal: Humor

Brand: Tulipan

Continent: South America

Copy: Kids later

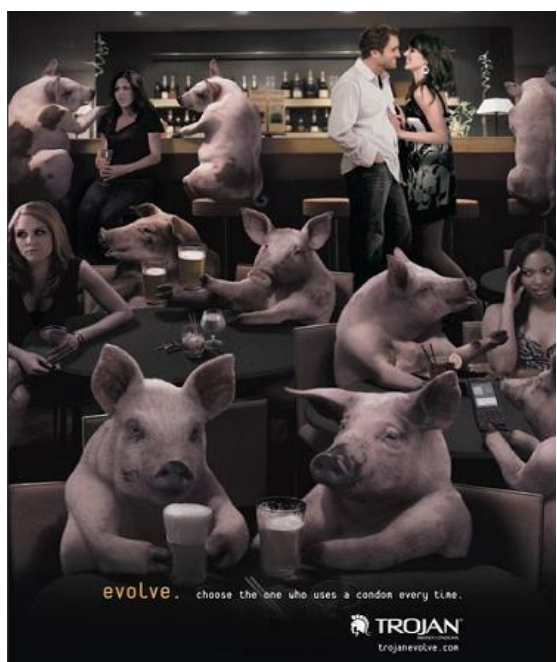

Appeal: Humor

Brand: Trojan

Continent: United States

Copy: Choose the one who uses a condom every time. 


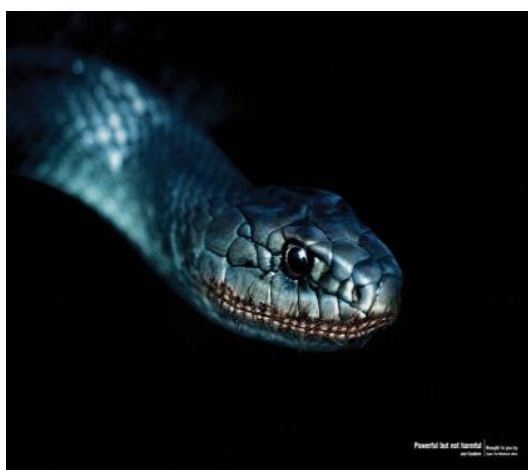

Appeal: Fear

Brand: SuanYai

Continent: Asia

Copy: Powerful but not harmful

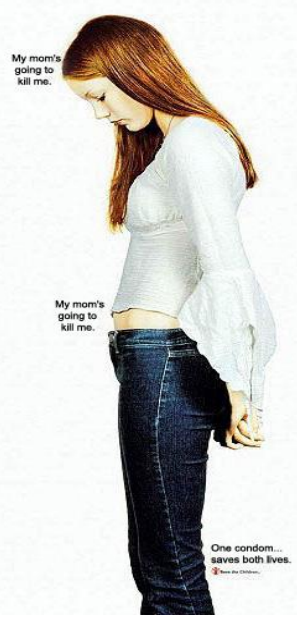

Appeal: Sadness

Continent: South America

Copy: One condom saves both lives

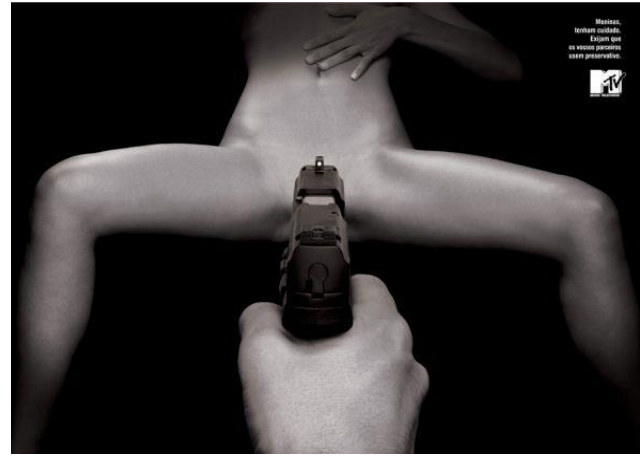

Appeal: Fear

Company: MTV

Continent: Europe

Copy: Demand that your partner wear a condom

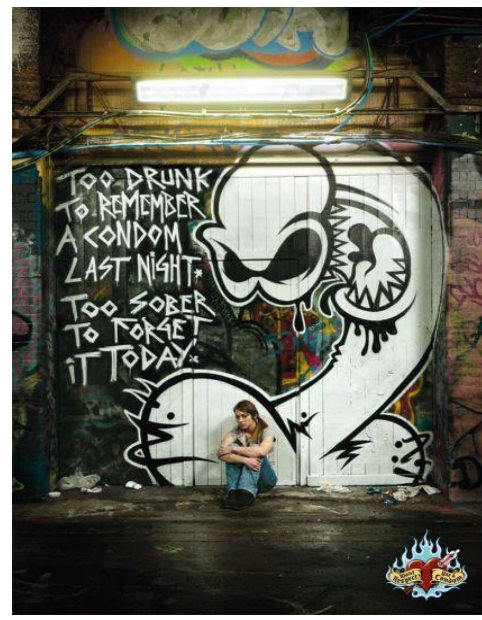

Appeal: Sadness

Company: COL

Continent: South America

Copy: Too drunk to remember a condom last night.

Too sober to forget it today. Want respect? Use a condom. 
Table 1. The use of emotional appeals in condom ads

\begin{tabular}{|l|l|l|l|l|l|l|l|l|l|l|}
\hline Appeal & \multicolumn{2}{|l|}{ Asia } & \multicolumn{2}{|l|}{ Europe } & \multicolumn{2}{l|}{ North } & \multicolumn{2}{l|}{ South } & \multicolumn{2}{l|}{ Total } \\
& No. & $\%$ & No. & $\%$ & No. & $\%$ & No. & $\%$ & No. & $\%$ \\
\hline Fear & 6 & 20 & 5 & 16.7 & 1 & 3 & 4 & 13.3 & 16 & 16 \\
\hline Humor & 24 & 80 & 25 & 83.3 & 29 & 97 & 24 & 80 & 102 & 102 \\
\hline Sadness & 0 & 0 & 0 & 0 & 0 & 0 & 2 & 6.7 & 2 & 2 \\
\hline Total & 30 & 100 & 30 & 100 & 30 & 100 & 30 & 100 & 120 & 100 \\
\hline
\end{tabular}

\section{Naked Bodies and Sexual Scenes}

The second research question asks to what extent naked bodies or sexual scenes were present in the condom ads and if the four places differ in terms of the presence of these visual elements in the ads. As Table 2 shows, about $87 \%$ of the sample did not show naked bodies or sexual scenes, suggesting caution and wariness with the use of such images in different cultural settings. These images were observed only in about 16 ads (13\%), the majority of which (13 ads) was published in Europe; none came from North America. Examples of ads that made use of these sexual representations are shown in Figure 2. 
Figure 2. Examples of ads that show naked bodies or sexual scenes

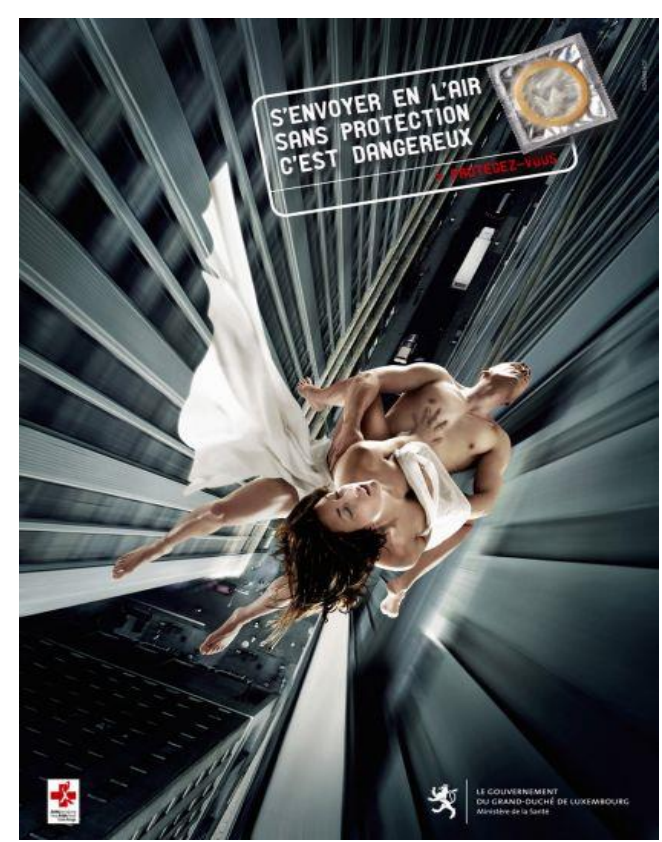

Brand: Ministère de la Santé

Continent: Europe

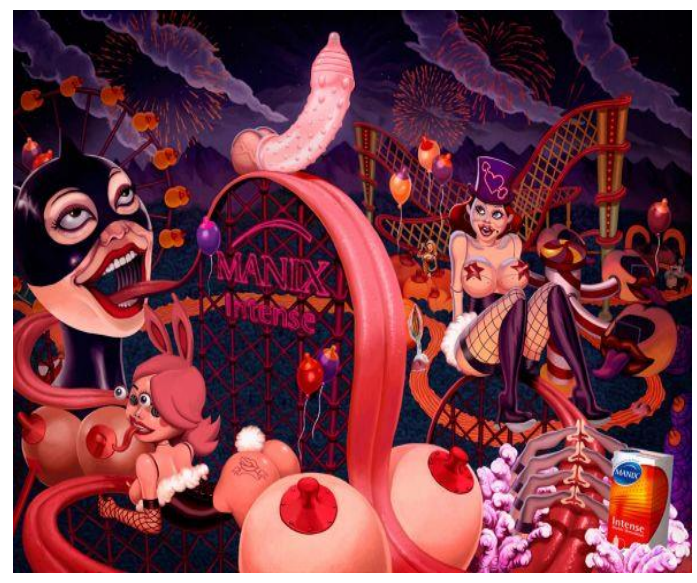

Brand: Manix

Continent: Europe

Copy: To be sent in the air without

protection is dangerous.

Table 2. The presence of naked bodies or sexual scenes in condom ads

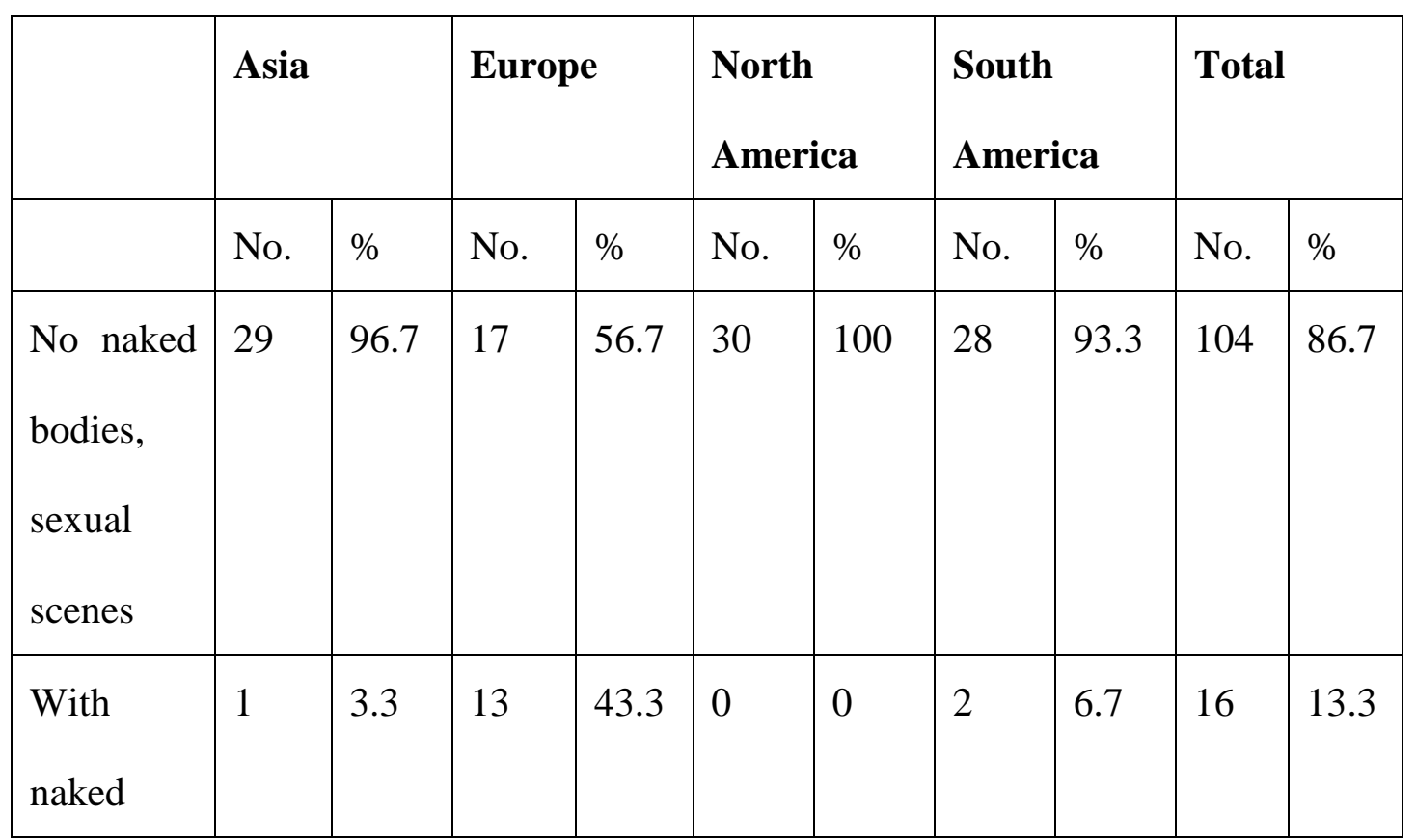




\begin{tabular}{|l|l|l|l|l|l|l|l|l|l|l|}
\hline bodies, & & & & & & & & & & \\
sexual & & & & & & & & & & \\
scenes & & & & & & & & & & \\
\hline Total & 30 & 100 & 30 & 100 & 30 & 100 & 30 & 100 & 120 & 100 \\
\hline
\end{tabular}

The results of a chi-square test suggest that the four locations differed significantly in terms of the use of highly charged sexual images $\left(x^{2}=31.73, d f=3, p=.000\right)$. Europe led the pack in the deployment of such images that were observed in 13 print ads. The same type of visuals were rarely seen in Asia and South America. No ads that displayed naked bodies and sexual scenes were found in North America.

This finding lends support to the characterization that Europeans are more involved sensually with each other, leading to closer interpersonal relationships (Hall, 1969). Also, there is a general perception that the continent is more sexually liberated and sexually disinhibited than the rest of the world. Consequently, Europeans are more tolerant and receptive to sexual appeals and nudity in advertising, whereas in many places, especially in Asia and Latin America, this form of advertising is considered risqué. European ads are thus likely to use sexual appeals more often than others.

\section{Visual Metaphors}

The third research question looked for the presence of visual metaphors and the differences among the four continents in terms of metaphor use. Table 5 shows that only $16 \%$ (19 ads) made use of a metaphorical device. The frequency distribution of these ads is shown in Table 3. To determine whether the four continents differed in their use of metaphors, a chi-square test was conducted. The results were significant $\left(x^{2}=22.70, d f=3, p=.000\right)$. Of the 19 ads with 
metaphors, 12 saw print in Asia, six were published in Europe, and only one was observed in North America. The South American ads did not display metaphors at all. Examples of ads that made use of these metaphors are shown in Figure 3.

Figure 3. Examples of visual metaphors used in condom print ads

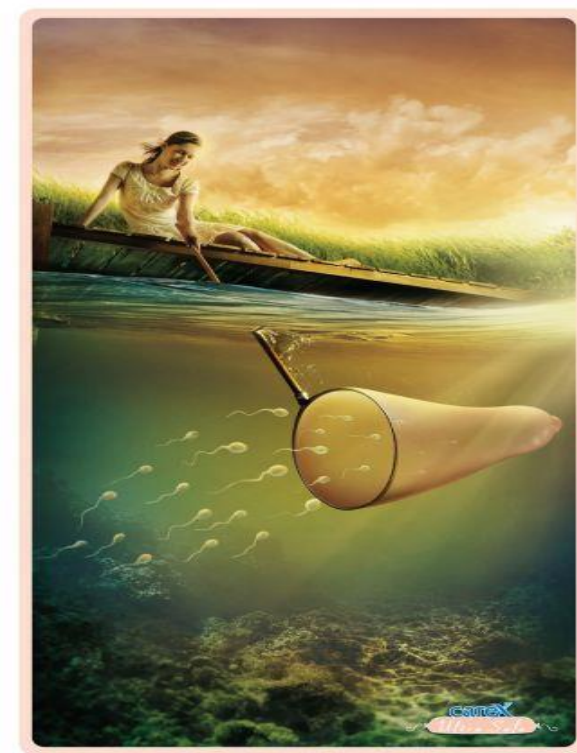

Brand: Carex

Continent: Asia

Copy: Carex ultra safe

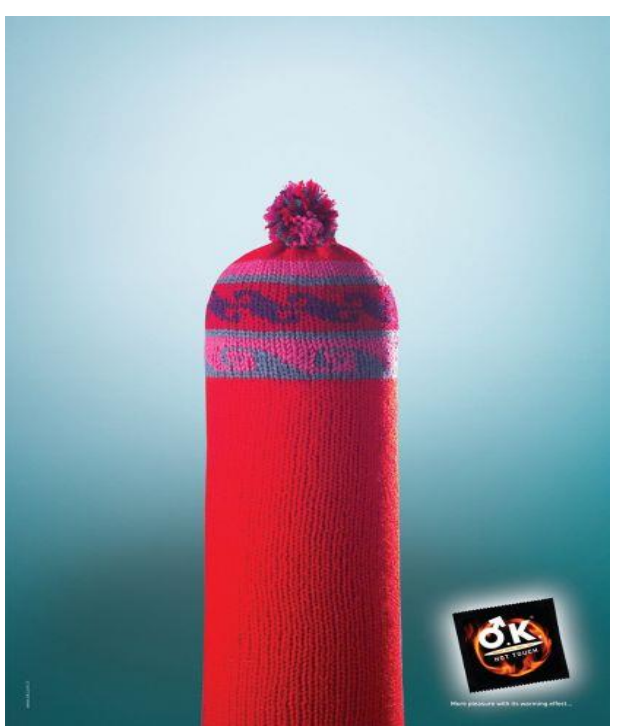

Brand: OK

Continent: Asia

Copy: More pleasure with its warming effect..

Table 3. The presence of visual metaphors in condom ads

\begin{tabular}{|c|c|c|c|c|c|c|c|c|c|c|}
\hline & \multicolumn{2}{|c|}{ Asia } & \multicolumn{2}{|c|}{ Europe } & \multicolumn{2}{|c|}{$\begin{array}{l}\text { North } \\
\text { America }\end{array}$} & \multicolumn{2}{|c|}{$\begin{array}{l}\text { South } \\
\text { America }\end{array}$} & \multicolumn{2}{|c|}{ Total } \\
\hline & No. & $\%$ & No. & $\%$ & No. & $\%$ & No. & $\%$ & No. & $\%$ \\
\hline $\begin{array}{l}\text { No } \\
\text { metaphors }\end{array}$ & 18 & 60 & 24 & 80 & 29 & 96.7 & 30 & 100 & 101 & 84.2 \\
\hline With & 12 & 40 & 6 & 20 & 1 & 3.3 & 0 & 0 & 19 & 15.8 \\
\hline
\end{tabular}




\begin{tabular}{|l|l|l|l|l|l|l|l|l|l|l|}
\hline metaphors & & & & & & & & & & \\
\hline Total & 30 & 100 & 30 & 100 & 30 & 100 & 30 & 100 & 120 & 100 \\
\hline
\end{tabular}

The fourth research question aimed at identifying the visual metaphors present in the condom ads and how the four continents differed on this regard. As listed in Table 4, the ads distributed in Asia displayed the most number of metaphors (15), Europe came in a poor second (5 metaphors). This suggests a greater propensity in Asia to make use of symbols that liken condoms to common, everyday objects to demonstrate their functions. The multiplicity of metaphors in the Asian context suggests the complex semiotic space Asians navigate. This may have resulted from the diverse cultures that comprise this continent. Some of its countries rank at the top in terms of gross domestic product; other less developed and smaller nations are overshadowed by neighbors that demonstrate faster economic growth (de Beer and Merrill, 2009). Countries across the region also have different types of government that promote or restrict the degree of freedom their media systems enjoy. The numerous languages, political systems, and national economic status that can be found in this continent are partly attributable to a rich history, a factor that must have spawned an equally rich visual lexicon. 
Table 4. Visual metaphors shown in the ads

\begin{tabular}{|l|l|}
\hline Place & Metaphors used \\
\hline Europe & Beanie hats \\
\hline & Bubbles \\
\hline & Fire attire \\
\hline & Gun \\
\hline Asia & Rubber gums \\
\hline & Balloon \\
\hline & Bananas without skins \\
\hline & Butterfly net \\
\hline & Feather \\
\hline & Firefly net \\
\hline & Fishing net \\
\hline & Light case \\
\hline & Maze \\
\hline Rorth America & Drying machine \\
\hline & Sneaker with mouth that looks like it has been sewn shut \\
\hline & Spider with sewed mouth \\
\hline & Wortoise without shelter \\
\hline & \\
\hline & \\
\hline &
\end{tabular}

The rich metaphor menu Asia exhibited is in accordance with Hall's (1981) description of a high-context culture in which a message is interpreted based not only on its content but on the situation, or context, in which the message occurs. The hidden or suggestive meanings that 
may be alluded to indirectly by the use of metaphorical devices, for example, are important. On the other hand, metaphor use is less expected in the low-context cultures of North America and Europe where messages are direct and must be explicitly stated or the meaning ran the risk of being lost (Hall, 1981).

\section{Visual Themes}

What are the frames present in the condom ads? Were the four places different in terms of the frames exhibited by the ads? The results, shown in Table 9, indicate that across the three continents, condoms were marketed to bolster the notion that they have the ability to heighten sexual pleasure. The results of a chi-square test suggest that the four continents significantly differed in their deployment of these visual themes $\left(x^{2}=19.389, \mathrm{df}=6, \mathrm{p}=.004\right)$. Of the four continents, Europe made the most use of ads aimed at correcting the misapprehension that condom use somehow reduces the quality of the sexual experience. Europe also had the highest percentage of ads that promoted condoms to prevent HIV/AIDS in recognition of the need to halt an epidemic that has ravaged much of Africa. Considering that the continent has a relatively low birth rate, it was not surprising that Europe also had the lowest number of ads that exhibited the pregnancy prevention theme.

That condoms do not dampen the sexual experience also was the most frequently observed theme in the Asian ads, followed by the HIV/AIDS prevention theme. For a continent that continues to experience a high population growth rate, the lower incidence of ads that display the pregnancy prevention theme went against expectations. In North America, enhancing sexual pleasure was the most commonly occurring theme in the ads, followed by the theme of using condoms as a birth control device. Despite the continuing threat posed by HIV/AIDS in the continent, this frame was the least observed in the North American ads. 
Preventing pregnancy was the dominant visual frame for South America. The continent made the most use of condom ads that displayed this theme, indicating that advertisers were acutely aware of the need to curb population growth in a continent composed mainly of developing nations. South America also exhibited the least number of ads that highlighted the notion that condoms enhance the sexual experience. Examples of ads that demonstrated these themes are shown in Figure 4.

Figure 4. Examples of ads that display the three themes

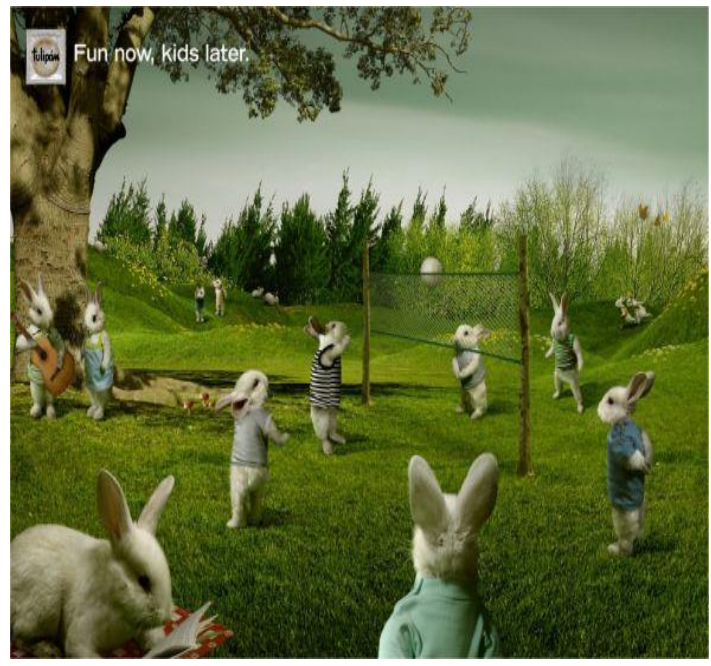

Theme: Condoms to prevent pregnancy

Brand: Tulipan

Continent: South America

Copy: Fun now, kids later

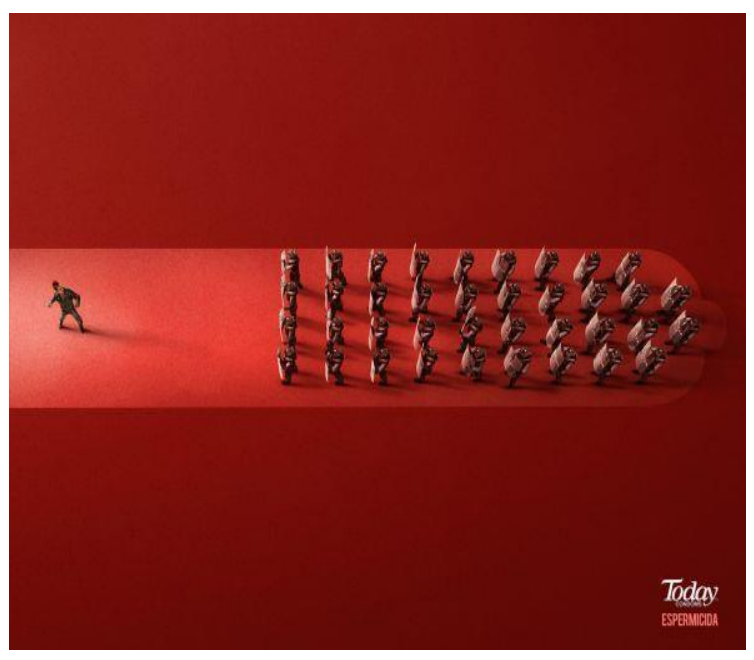

Theme: Condoms to prevent pregnancy Brand: Today

Continent: South America

Copy: Long action 


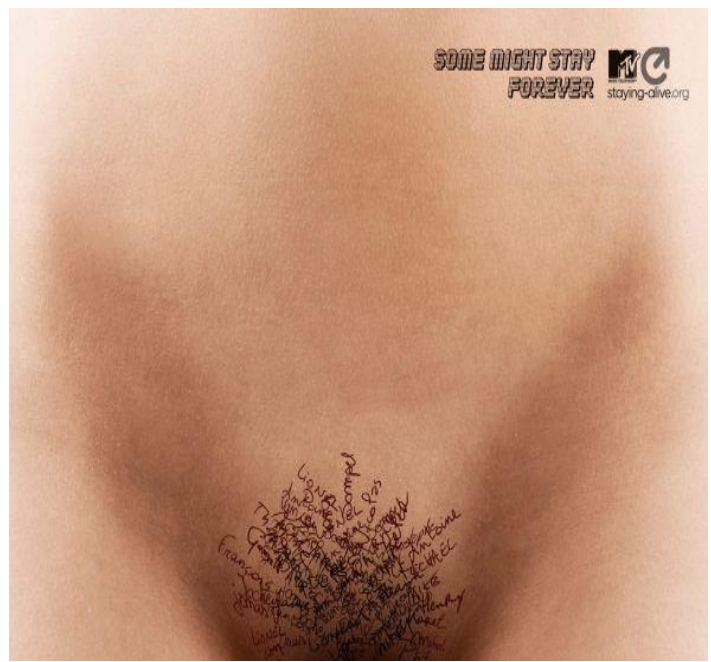

Theme: Condoms to prevent HIV/AIDS

Company: MTV

Continent: Europe

Copy: Some might stay forever.

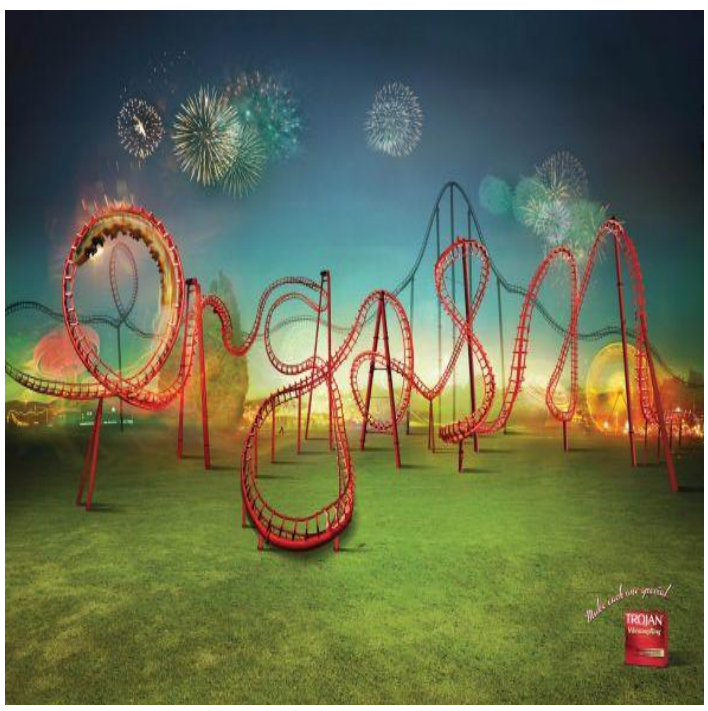

Theme: Condoms to enhance sexual Theme: Condoms to enhance sexual pleasure pleasure

Brand: Trojan

Continent: North America

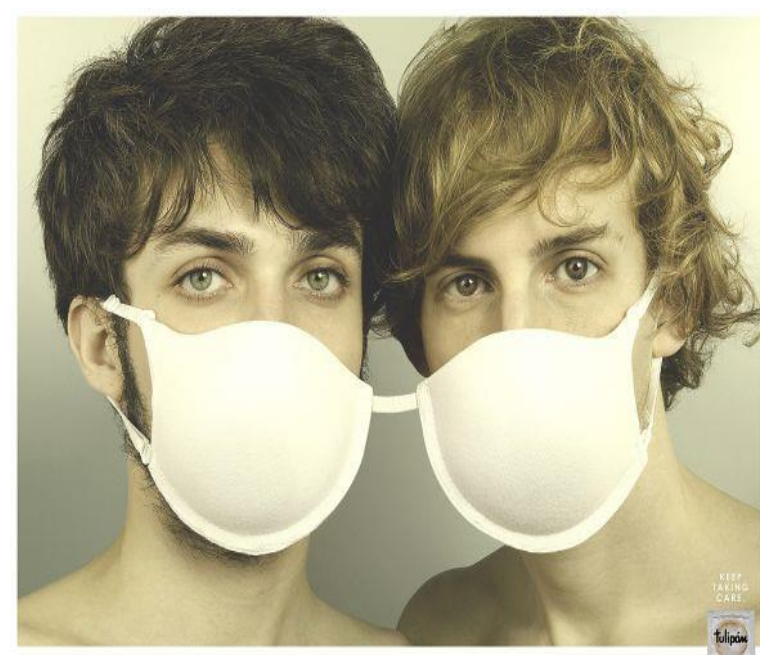

Theme: Condoms to prevent HIV/AIDS

Brand: Tulipan

Continent: South America

Copy: Keep taking care.

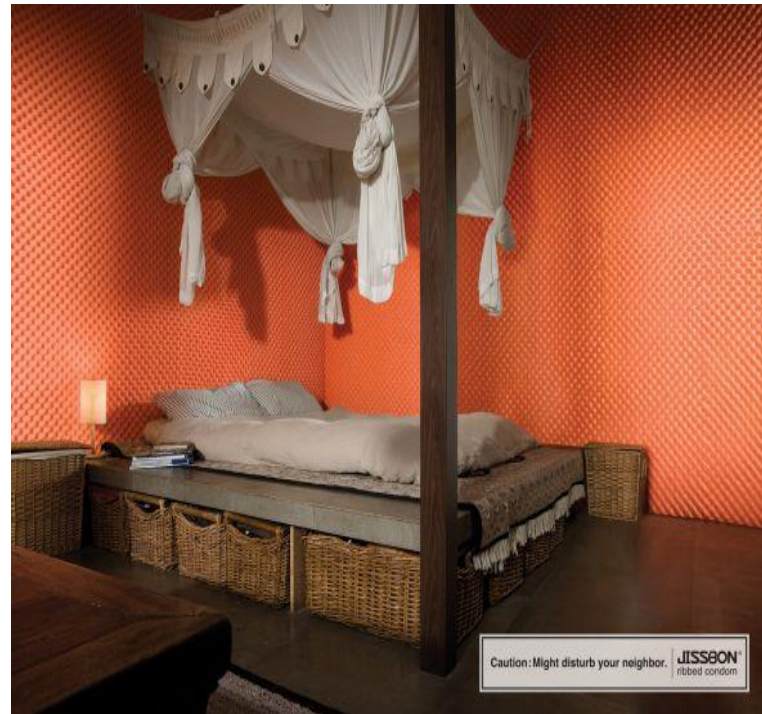

Brand: Jissbon Ribbed

Continent: Asia

Copy: Caution: Might disturb your neighbor.

Copy: Make each one special. 
Table 5. Dominant themes

\begin{tabular}{|c|c|c|c|c|c|c|c|c|c|c|}
\hline & \multicolumn{2}{|c|}{ Asia } & \multicolumn{2}{|c|}{ Europe } & \multicolumn{2}{|c|}{$\begin{array}{l}\text { North } \\
\text { America }\end{array}$} & \multicolumn{2}{|c|}{$\begin{array}{l}\text { South } \\
\text { America }\end{array}$} & \multicolumn{2}{|c|}{ Total } \\
\hline & No. & $\%$ & No. & $\%$ & No. & $\%$ & No. & $\%$ & No. & $\%$ \\
\hline $\begin{array}{l}\text { Condoms to prevent } \\
\text { pregnancy }\end{array}$ & 8 & 26.7 & 2 & 6.7 & 10 & 33.3 & 16 & 53.3 & 36 & 30 \\
\hline $\begin{array}{l}\text { Condoms to prevent } \\
\text { HIV/AIDS }\end{array}$ & 10 & 33.3 & 13 & 43.3 & 5 & 16.7 & 8 & 26.7 & 36 & 30 \\
\hline $\begin{array}{l}\text { Condoms to } \\
\text { enhance sexual } \\
\text { pleasure }\end{array}$ & 12 & 40 & 15 & 50 & 15 & 50 & 6 & 20 & 48 & 40 \\
\hline Total & 30 & 100 & 30 & 100 & 30 & 100 & 30 & 100 & 120 & 100 \\
\hline
\end{tabular}

\section{Conclusions}

This study examines condom advertising expressions across cultures that clearly have very dissimilar value systems. Content analysis was employed to identify the advertising appeals used, the use of naked bodies or sexual scenes, the presence of metaphors, the kinds of metaphorical devices employed, and the dominant themes displayed in the advertisements. The findings show that $85 \%$ of the combined sample of condom ads used humor appeal to persuade customers. This may be because humor has long demonstrated its capacity to attract attention and enhance message recall. Condom advertisers also did not exploit nakedness and sexual scenes to drive home their messages. Only $13 \%$ of the total number of advertising pieces analyzed displayed naked bodies or sexual scenes, the majority of which was found in ads published in Europe. Few ads, only 16\%, used metaphorical devices to communicate condom functions. Of these, the majority were observed in ads that saw print in Asia. The 
visual metaphors mainly illustrated the value of condoms in blocking sperm cells.

The four continents differed markedly in the visual frames that dominated these ads. In Europe, Asia, and North America, the dominant frame was the enhancement of sexual pleasure. In South America, the major theme focused on preventing pregnancy. The continent's ads also drummed up safe sex practices, particularly the need to control the spread of HIV/AIDS in the shadow of a very strong Catholic influence.

As with many of the studies that have investigated cross-cultural advertising, the findings of this study suggest that the advertisements produced in one country cannot simply be standardized or directly translated for use in another. The results provide insights into the differences that may exist in the advertising expressions in four continents having many socioeconomic and other differences. For example, marketers attempting to advertise in Europe should be aware of the greater openness to emotional appeals, sex appeals, and humor in that continent and adapt accordingly. One must keep the following limitations in mind when interpreting the results of this study. First, more detailed studies should be carried out to compare advertising content by specific product category. The differences in advertising expression may be due to different products being advertised. It is possible, for example, that technologically demanding products, as well as new products, might call for the use of more rational appeals regardless of culture. Likewise, humor may be more acceptable for some product categories in one continent compared to the next. Second, the results reflect the subjective views of only two coders. This may be particularly troublesome for the detection of emotional appeals. Third, it may not be appropriate to generalize the findings of this study to other media. The generalizability of the results also is severely limited by the relatively small sample size (only 30 ads were examined per continent). Fourth, the cross-continent samples 
also precluded an analysis of differences between countries. Future investigations that adopt such an approach are likely to produce more culturally sensitive and nuanced results.

It is evident that the cultural differences among these continents account for some of the variations in print advertisements examined in this study. Also to be considered, however, are factors other than culture, which may have an effect on the content of an advertisement. This includes product type, the country's preferred medium of advertising, and the target to which the advertisement is appealing. These factors must be examined more thoroughly to determine how large a portion of the difference in advertisements is attributable to cultural determinants. 


\section{References}

Alden, D. L., Hoyer, W. D., \& Lee, C. Identifying global and culture-specific dimensions of humor in advertising: A multinational analysis. Journal of Marketing, 57, 64-75.

Ambekar, A. (2009). Different types of advertising appeals. Retrieved from http://www.articleswave.com/advertising-articles/types-of-advertising-appeals.html.

Belch, G. E., \& Belch, M. A. (1998). Advertising and promotion. New York: McGraw-Hill.

Bello, D. C., Pitts, R. E., \& Etzel, M. J. (1983). The communication effects of controversial sexual content in television programs and commercials. Journal of Advertising, 12(3), $32-42$.

Berkman, H. W., \& Gilson, C. C. (1987). Advertising, concepts and strategies. New York: Random House.

Biswas, A., Olsen, J. E., \& Carlet, V. (1992). A comparison of print advertisements from the United States and France. Journal of Advertising, 21(4), 73-81.

Bowers, J. W., \& Osborn, M. M. (1966). Attitudinal effects of selected types of concluding metaphors in persuasive speeches. Speech Monographs, 33, 147-55.

Chu, F. G. (1996). Strategy analysis of advertising rational appeals strategy. Journal of Advertising and Public Relations, 8, 1-26.

De Beer, A., \& Merrill, J. (Eds.). (2009). Global journalism: Topical issues and media systems. Boston: Pearson Education, Inc.

Entman, R. M. (1991). Framing United States coverage of international news-Contrasts in narratives of the KAL and Iran Air incidents. Journal of Communication, 41(4), 6-27.

Eppler, M. J. (2003). The image of insight: The use of visual metaphors in the communication of knowledge, in: Tochtermann, K., Maurer, H. (Eds.) Proceedings of the third international conference on Knowledge Management Iknow, 82-88.

Fetto, J. (2001). Where's the lovin'? American Demographics, 23(2), 10-11. 
Frith, K. T., \& Mueller, B. (2003). Advertising and societies. New York: Peter Lang.

Gallup \& Robinson Advertising and Marketing Research (2011). Sex in advertising: An evolution of more than 80 years of OHHHS and AHHHS. Retrieved from http://www.gallup-robinson.com/essay1.html.

Gamson, W. A., \& Stuart, D. (1992). Media discourse as a symbolic contrast: The bomb in political cartoons. Sociological Forum, 7(1), 55-86.

Goffman, E. (1974). Frame analysis: An essay on the organization of experience. New York: Harper \& Row.

Gordon, J. (2005). Presentations that change minds: Strategies to persuade, convince, and get results. New York: McGraw-Hill.

Hall, E. T. (1981). Beyond culture. New York: Random House.

Huang, M. (1997). Exploring a new typology of emotional appeals: Basic versus social emotional advertising. Journal of Current Issues and Research in Advertising, 19, 23-37.

Kaplan, S. J. (1990). Visual metaphors in the representation of communication technology. Critical Studies in Mass Communication, 7(1), 37-47.

Kaplan, S. J. (1992). A conceptual analysis of form and content in visual metaphors. Communication, 13(2), 197-209.

Kotler, P. (1991). Marketing management: Analysis, planning, implementation and control ( $7^{\text {th }}$ ed.). Upper Saddle River, NJ: Prentice Hall.

Lakoff, G., \& Johnson, M. (1980). Metaphors we live by. Chicago: University of Chicago.

Levit, M. (2005). Humor in advertising. Retrieved from http://ezinearticles.com/?Humor-in-Advertising\&id=27905.

McQuarrie, E. F., Phillips, B. J. (2004). Indirect persuasion in advertising:

How consumers process metaphors presented in pictures and words. Retrieved from 
http://www.acrwebsite.org/topic.asp?artid=291.

Mitchell, M. M., Brown, K. M., Morris-Villagran, M., \& Villagran, P. D. (2001). The effects of anger, sadness and happiness on persuasive message processing: A test of negative state relief model. Communication Monograph, 68, 347-359.

Morgan, S. E., \& Reichert, T. (1999). The message is in the metaphor: Assessing the comprehension of metaphors in advertisements. Journal of Advertising, 28(4), 1-12.

Morris, P. (2011). Culture and metaphors in advertising: France, Germany,

Italy, the Netherlands, and the United States. International Journal of Communication, 5, $942-968$

Morris, P. K., \& Waldman, J. A. (2011). Culture and metaphors in advertising:

France, Germany, Italy, the Netherlands, and the United States. International Journal of Communication, 5, 942-968.

Mueller, B. (1991). An analysis of information content in standardized vs. specialized multinational advertisements. Journal of International Business Studies, 22, 23-39.

Nelson, M. \& Peak, H. (2005). Cross-cultural differences in sexual advertising content in a transnational women's magazine. Sex Roles, 53, 347.

Parkinson, B. (1995). Ideas and realities of emotion. London: Rutledge.

Peppers, S. C. (1942). World hypotheses. Los Angeles, CA: University of California Press.

Reichert, T. (2002). Sex in advertising research: A review of content, effects, and functions of sexual information in consumer advertising. Annual Review of Sex Research, 13, 241-73.

Rogers, R. W. (1983). Cognitive and physiological processes in fear appeals and attitude change: A revised theory of protection motivation. In T. C. John \& E. P. Richard (Eds), Social psychology: A sourcebook (pp.153-176). New York: Guilford.

Rothschild, M. L. (1987). Marketing communications, Lexington, MA: D.C. Heath and 


\section{Company.}

Scheufele, D. (2007). Framing, agenda setting, and priming: The evolution of three media effects models. Journal of Communication, 57(1), 9-20.

Schiffman, L. G., \& Kanuk, L. L. (2007). Consumer behavior ( $9^{\text {th }}$ ed.). Upper Saddle River, NJ: Prentice Hall.

Shoemaker, P. J., \& Reese, S. D. (1996). Mediating the message: Theories of influences on mass media content. New York: Longman.

Scott, W. A. (1955). Reliability of content analysis: The case of nominal scale coding. Public Opinion Quarterly, 19, 321-325.

Stemler, S. (2001). An overview of content analysis. Practical Assessment, Research \& Evaluation, 7, 17. Retrieved March 13, 2012 from

http://PAREonline.net/getvn.asp?v=7\&n=17.

Sternthal, B., \& Craig, C. S. (1974). Fear appeals: Revisited and revised. Journal of Consumer Research, 1(3), 22-34.

Tanner Jr., J. F., Hunt, J. B., \& Eppright, D. R. (1991). The protection motivation model: A normative model of fear appeals. Journal of Marketing, 55(3), 36-45.

Taylor, C. \& Raymond, M. (2000). An analysis of product category restrictions in advertising in four major East Asian markets. International Marketing Review, 17(3), 299.

Tansey, R., Hyman, M. R., \& Zinkhan. G. M. (1990). Cultural themes in Brazilian and U.S. auto ads: A cross-cultural comparison. Journal of Advertising, 19(2), 30-39.

Tucker, L. R. (1998). The framing of Calvin Klein: A frame analysis of media discourse about the August 1995 Calvin Klein jeans advertising campaign. Critical Studies in Mass Communication, 15(2), 141-157.

Wallbott, H. G., \& Scherer, K. R. (1986). How universal and specific is emotional experience? Evidence from 27 countries on five continents. Social Science Information, 25, 
$357-369$.

Wilke, M. (2001). Changing standards: Condom advertising on American television: A special report of the Kaiser Daily Reproductive Health Report. Menlo Park, CA: National Journal Group Inc. and Henry J. Kaiser Family.

Zinkhan, G. M., \& Gelb, B. D. (1990). Repetition, social settings, perceived humor, and wearout. In M. E. Goldberg, G. Gorn and R. W. Pollay (Eds.), Advances in Consumer Research, vol. 17 (pp. 438-441). Provo, UT: Association for Consumer Research. 